\title{
Occupational Exposures and the Risk of Amyotrophic Lateral Sclerosis
}

\author{
Tracy L. Peters ${ }^{1,2}$, Freya Kamel ${ }^{2}$, Cecilia Lundholm ${ }^{1}$, Maria Feychting ${ }^{3}$, Caroline E. \\ WeibulI ${ }^{1}$, Dale P. Sandler ${ }^{2}$, Pernilla Wiebert ${ }^{4}$, Pär Sparén ${ }^{1}$, Weimin Ye ${ }^{1}$, and Fang Fang ${ }^{1}$ \\ ${ }^{1}$ Department of Medical Epidemiology and Biostatistics, Karolinska Institutet, Stockholm, Sweden \\ ${ }^{2}$ Epidemiology Branch, National Institute of Environmental Health Sciences, Research Triangle \\ Park, North Carolina, USA \\ ${ }^{3}$ Unit of Epidemiology, Institute of Environmental Medicine, Karolinska Institutet, Stockholm, \\ Sweden \\ ${ }^{4}$ Unit of Occupational Medicine, Institute of Environmental Medicine, Karolinska Institutet, \\ Stockholm, Sweden
}

\begin{abstract}
Objectives-To examine the associations of specific occupations and occupational exposures with the risk of amyotrophic lateral sclerosis (ALS) in the Swedish population.

Methods-A nested case-control study was conducted in Sweden. ALS patients diagnosed during 1991-2010 ( $\mathrm{n}=5,020)$ were identified from the National Patient Register and five controls per case $(n=25,100)$ were randomly selected from the general Swedish population, individually matched to cases by birth year and sex. Occupational history was obtained from the Swedish Censuses in 1970, 1980, and 1990. The Nordic Occupational Cancer Study Job Exposure Matrix was used to identify exposures related to individual occupations. Conditional logistic regression was used to estimate odds ratios (ORs) and their 95\% confidence intervals (CIs).
\end{abstract}

Results-Higher risk of ALS was associated with precision-tool manufacturing (OR: 1.68, 95\% CI: $1.11,2.52)$ and glass, pottery and tile work (OR: 1.76, 95\% CI: 1.03, 3.00), whereas lower risk was associated with textile work (OR: $0.44,95 \%$ CI: $0.21,0.91)$. None of the examined occupational exposures were associated with ALS risk overall. However, among individuals younger than 65 years of age, an association with a higher risk of ALS was found for formaldehyde (OR: 1.29, 95\% CI: 1.00, 1.65), and an association with a lower risk of ALS was found for methylene chloride (OR: 0.49, 95\% CI: 0.26, 0.93).

Corresponding Author: Tracy L. Peters, Department of Medical Epidemiology and Biostatistics, Karolinska Institutet, P.O. Box 281, 17177 Stockholm, Sweden, Telephone: +46 (0) 8-524 839 433, tracy.peters@ gmail.com.

Competing interests

Authors have none to disclose.

Contributors

Study concept and design: Peters, Kamel, Lundholm, Feychting, Weibull, Sparén, Ye, Fang, Sandler. Study analysis and interpretation of data: Peters, Kamel, Weibull, Lundholm, Fang. Drafting of the manuscript: Peters, Fang. Critical revision of the manuscript: All authors. 
Conclusions-We identified several occupations and occupational exposures that may be associated with the risk of ALS in Sweden. Occupational history obtained from censuses every ten years remains a limitation of the study.

\section{Keywords}

Amyotrophic Lateral Sclerosis; Job Exposure Matrix; Occupation

\section{INTRODUCTION}

Amyotrophic lateral sclerosis (ALS) is a neurodegenerative disorder affecting both lower and upper motor neurons.[1] Death usually occurs within three to five years after onset of symptoms related to ALS.[2] Age, sex and family history are known risk factors for ALS.[2] Among non-genetic factors potentially related to ALS, occupations are frequently examined. [3] Specific exposures related to the occupations may be the underlying reasons for any observed associations between various occupations and ALS.

Occupational exposure to lead, other metals, solvents and formaldehyde have been reported to be associated with ALS risk in some studies.[4-9] Other studies have however failed to detect such associations.[10,11] Most previous studies collected occupational data retrospectively, and, given the low incidence of ALS, most studies also enrolled relatively small numbers of ALS patients and therefore lacked statistical power to detect real associations.[11]

Job exposure matrices (JEMs) have been used to evaluate the association of ALS risk with only a limited number of occupational exposures, mainly electromagnetic fields (EMF), electric shock and physical activity.[12-15] To our best knowledge, no studies have used a JEM to explore the association of solvents, metals or formaldehyde with ALS risk.

We aimed to investigate the impact of specific occupations and their related exposures on ALS risk in Sweden, using an objective measurement of occupation, the Nordic Occupational Cancer Study Job Exposure Matrix (NOCCA-JEM),[16] and a large nationwide study sample.

\section{MATERIAL AND METHODS}

\section{Study population}

The study population was composed of all individuals who were born in Sweden during 1901-1970 and included in the 1990 Swedish Population and Household Census $(\mathrm{N}=5,763,437)$. The Census was conducted by Statistics Sweden and covered all individuals who had lived in Sweden for at least one year. The Census included a questionnaire that collected information about region of residence, citizenship, gender, and birthdate.[17]

\section{Swedish registers and follow-up}

The National Patient Register (NPR) was started in 1964/1965 by the Swedish National Board of Health and Welfare to collect information on all hospital discharges; it achieved nationwide coverage in 1987. The NPR has also collected information on hospital-based 
outpatient specialist visits since 2001. Information recorded in the NPR includes the dates of admission, discharge, and specialist visit, as well as multiple diagnoses. Primary and secondary diagnoses are recorded for each clinic visit and are coded according to the Swedish revisions of the International Classification of Diseases (ICD): ICD-9 during 19871996 and ICD-10 from 1997 to present. The Migration Register records information on emigration and immigration dates of registered residents in Sweden. The Cause of Death Register has been ongoing since 1952 and includes date and causes of death. The Swedish Education Register is updated yearly and contains information on the highest level of education for all individuals aged 16-74. The personal identity number (PIN) is a unique identifier for each resident of Sweden. Using PINs, we followed the study population via linkages to the NPR, the Migration Register, and the Cause of Death Register, between January 1, 1991, and December 31, 2010.

\section{Case identification}

ALS patients were identified as those with a record in the NPR (inpatient visits from 1991 to 2010 and outpatient visits from 2001 to 2010) where ALS was a primary or secondary diagnosis (ICD-9335C and ICD-10 G12.2). In the Swedish Revisions of the ICD codes, 335C (ICD-9) was used for ALS exclusively, whereas G12.2 (ICD-10) was used both for ALS and other motor neuron diseases; the latter are however much rarer than ALS. The date of the first clinic visit for ALS was used as the date of ALS diagnosis. Follow-up ended at ALS diagnosis or was censored at migration out of Sweden, death, or December 31, 2010, whichever came first. A total of 5,020 individuals were identified as ALS patients during follow-up.

\section{Nested case-control study}

We conducted a nested case-control study within the study population described above. Using incidence density sampling, we randomly selected 25,100 controls (five per ALS case) from the study population still alive on the date of diagnosis of the case; controls were individually matched to ALS cases by birth year and sex. Index date was defined as the date of ALS diagnosis for cases and date of selection (date of diagnosis of the matched case) for controls. Controls were free of ALS on the index date but could develop ALS later on and become a case $(\mathrm{N}=17)$.

\section{Occupation}

We linked cases and controls to the 1970,1980, and 1990 Swedish censuses to ascertain their individual occupational histories. The Swedish censuses have a three level ordering system of occupations, from a one digit level, which organizes the occupations into broad categories, to a three digit level, which contains information on more specific occupations. A person could only have one occupation listed in a particular census. However, if a person had three different occupations in three different censuses this individual was considered to be exposed to all three occupations. Administrative and clerical work (jobs related to government administration, business administration, book-keeping, etc.) was used as the reference group for the occupation analyses because it likely does not involve appreciable exposure to neurotoxicants and there is little literature indicating that administrative and 
clerical work is associated with ALS.[18] Furthermore, it is one of the largest occupation groups.

\section{Occupational exposure: Nordic occupational cancer study - job exposure matrix}

Occupational exposures were assessed using the Swedish version of the job exposure matrix developed as part of the Nordic Occupational Cancer Study (NOCCA).[16] A JEM links occupations to profiles of specific workplace exposures. In the NOCCA-JEM, exposure is characterized by estimates of the prevalence and level of a specific exposure at specific calendar times.[16] The NOCCA-JEM includes 300 occupations and more than 20 agents and covers four time periods during 1945-1994.[16] We evaluated 12 of the over 20 agents previously suggested to be associated with ALS in the NOCCA-JEM: benzo (a) pyrene, chromium, iron, formaldehyde, nickel, lead, benzene, methylene chloride, toluene, perchloroethylene, 1,1,1-trichloroethane, and trichloroethylene. All occupations within the NOCCA-JEM are specific at a three-digit level, as in the Swedish censuses, and exposures from each occupation are combined to create an overall exposure; for example, lead exposure includes information from metal smelting workers, foundry workers, and others.

We further combined these 12 agents into three categories: metals + benzo (a) pyrene (i.e., lead, iron, nickel, chromium, benzo (a) pyrene), solvents (i.e., toluene, benzene, trichloroethylene, methylene chloride, perchloroethylene, 1,1,1,-trichloroethane), and formaldehyde. Metals + benzo (a) pryrene were combined because more than $90 \%$ of the occupations with exposures to metals or benzo (a) pyrene overlapped with each other.

We examined potential dose-response relationships of ALS risk with lead and formaldehyde, two occupational exposures that have been investigated in several studies. $[4,5,9]$ To construct an exposure metric, we multiplied the prevalence of exposure $(\mathrm{P})$ and the annual mean level of exposure (L) in a specific occupation at the time of a census to create an extent of exposure expressed as $\mathrm{P} * \mathrm{~L}$ in $\mathrm{mg} / \mathrm{m}^{3}$.[16] $\mathrm{P} * \mathrm{~L}$ was calculated for each occupation category in each census $(1970,1980$ and 1990) and averaged over censuses to calculate the extent of exposure for an individual. The exposure variable was further dichotomized at the median values of the controls in the analysis.

\section{Statistical analyses}

We used conditional logistic regression models to estimate odds ratios (ORs) and 95\% confidence intervals (CIs) for associations of ALS risk with occupations and occupational exposures. Since cases and controls were individually matched on sex (male/female) and birth year, the logistic models were conditioned on matching strata. In all models, we further adjusted for education (categorized as 9 years or less of education, 10-12 years of education, and university or $\mathrm{PhD})$.

For all analyses, in order to minimize the healthy worker effect,[19] we restricted the analyses to cases and controls with at least one occupation registered in any of the censuses ( $\mathrm{N}=4,567$ for cases and $\mathrm{N}=22,402$ for controls). To avoid potential reverse causality, we only included occupations listed in the censuses performed at least ten years before the index date. Furthermore, we conducted a sensitivity analysis among individuals $<65$ years old at the index date, because the majority of workers retire at this age in Sweden. 
In the analyses of all 12 occupational exposures, as well as the dose-response analyses for lead and formaldehyde, we further restricted the analyses to cases and controls who were either blue collar workers or farmers $(\mathrm{N}=2,647$ for cases and $\mathrm{N}=13,378$ for controls) since these exposures are rare among white collar workers. In the analysis of specific occupational exposures, individuals with no such exposure were used as the reference group. All 12 exposure items were mutually adjusted for one another in one model.

Statistical significance level in this study was defined as $\mathrm{p}<0.05$.

All statistical analyses were performed using SAS version 9.4 (SAS Institute, North Carolina, USA).

This study was approved in Stockholm, Sweden by the Regional Ethical Review Board.

\section{RESULTS}

Table 1 provides descriptive information about ALS cases and controls. Most ALS cases and controls were male, were born between 1923 and 1931, were aged 70-79 on the index date, had nine years or less of education, and lived in the central part of Sweden (Table 1). Cases had on average a slightly higher level of education than controls (Chi-square with three degrees of freedom $=12.0, p=0.0074)$. Cases and controls did not appear to have a clear difference in county of residence (Supplemental Figure 1).[20] The three counties where our cases and controls mainly resided included: Skåne (cases: 626 (12\%); controls: 3,114 (13\%)), Stockholm (cases: 911 (18\%); controls 4,114 (16\%)) and Västra Götaland (cases: 791 (16\%); controls: 4,288 (16\%)) (Supplemental Figure 1).[20]

In the analyses of occupations, we found positive associations with ALS for precision-tool manufacturing (OR: $1.68, \mathrm{CI}: 1.11,2.52$ ) and glass, pottery and tile work (OR: 1.76, CI: 1.03, 3.00) (Table 2). A positive association for health and nursing work was noted although not statistically significant (OR: 1.13, CI: 0.99, 1.29) (Table 2). We also found an inverse association between ALS and textile work (OR: 0.44, CI: 0.21, 0.91) (Table 2). Among cases and controls that were $<65$ years old on the index date, we found no statistically significant associations between any of the occupations and ALS (data not shown).

We found no clear association of ALS with any of the 12 occupational exposures in the entire study sample (Table 3). Among individuals $<65$ years old on the index date, however, we found a positive association of ALS with formaldehyde (OR: 1.29, CI: 1.00, 1.65) and an inverse association with methylene chloride (OR: 0.49, CI: 0.26, 0.93) (Supplemental Table $1)$.

We found no association with ALS for any of the three exposure groups (metals + benzo (a) pyrene, solvents, formaldehyde) in the entire study sample (Table 4). However, among individuals $<65$ years old, we found a positive association of ALS with formaldehyde (OR: 1.28, CI: 1.02, 1.61) (Supplemental Table 2).

No clear dose-response relationship was found between ALS and either lead or formaldehyde (Table 5). 
In general, ORs not adjusted for education didn't differ much from the fully adjusted results (data not shown).

\section{DISCUSSION}

In this nationwide nested case-control study, we found a positive association of ALS with precision-tool manufacturing and glass, pottery and tile work and an inverse association of ALS with textile work. Similar associations were however not noted among individuals younger than 65 years, i.e., before retirement. Among the occupational exposures evaluated, a positive association of ALS was noted for formaldehyde and an inverse association for methylene chloride among individuals younger than 65 years.

A few previous studies have investigated the associations of different occupations and occupational exposures with ALS risk in Sweden.[12, 21, 23] A cohort study explored magnetic field exposure based on a job exposure matrix and found no increased risk for ALS overall; however, the authors did find an increased risk of ALS among electrical and electronics workers.[21] A recent study used two electric shock and three magnetic field jobexposure matrices to study the impact of electric shock, electric occupations and occupational magnetic fields on the risk of ALS and found some support for an association between electric shocks and ALS risk.[12] In another study, more male ALS cases were farm workers, agricultural workers and office workers compared to the general male population in Sweden, whereas more female ALS cases were medical service workers compared to the general female population.[23] The category "medical service worker" includes registered nurses, midwives, attendants in psychiatric care, practical nurses and hospital orderlies, dental nurses, medical technicians, pharmacists, physiotherapists, occupational therapists, and health and nursing work. Specific occupational exposures including solvents were not associated with ALS risk in a case-control study among Swedish men.[22]

Studies from outside Sweden have also given mixed results. [4, 7, 9, 11, 24] A matched casecontrol study of ALS cases and controls in Pennsylvania, USA, found that self-reported occupational exposure to metals (lead and mercury) was associated with increased ALS risk; no association was however found for solvents (organic/chlorinated, aromatic).[24] Another study from the United States, found that workplace exposure to lead was associated with an increased risk of ALS overall and among smokers.[4] An Australian case-control study found no association for metals whereas there was an association of ALS with solvents and other chemicals.[7] In our study, we found no overall association between occupational exposure to metals and increased ALS risk.

Lead has been frequently explored as a possible risk factor for ALS and is known to be toxic to motor neurons.[9] A meta-analysis that included nine case-control studies found a doubled risk of ALS associated with occupational exposure to lead.[9] Apart from an odds ratio of 1.29 for exposure to a higher-than-median level of lead among individuals younger than 65 (not statistically significant), we did not find any association of lead with ALS. 
Methylene chloride is mainly used as a solvent and may be a human carcinogen.[25] A previous case-control study from New England found no association between methylene chloride and ALS risk.[4] Underlying reasons for the inverse association between methylene chloride and ALS risk noted among individuals $<65$ years of age in our study need to be explored.

We found an association of formaldehyde with ALS risk among individuals $<65$ years of age. This finding is supported by the fact that medical service workers - an occupation with high exposure levels of formaldehyde[26] - also had higher risk of ALS in a previous Swedish study[23] and a modest although not statistically significant increase of ALS risk in the present study. In contrast, in other studies, medical service workers, mainly health and nursing workers, did not appear to have a higher ALS risk.[23, 27] Only a few studies have specifically investigated formaldehyde in relation to ALS risk, and again they have yielded mixed results.[4, 28] A case-control study conducted in New England, USA, found no association between workplace formaldehyde and the risk of ALS, [4] whereas a prospective cohort study from the USA found formaldehyde exposure to be associated with an increased risk of ALS.[28] A cohort study investigated ALS mortality within occupations that were exposed to formaldehyde and found that men who had a high probability of exposure to formaldehyde had a higher rate of death from ALS; this association was not found in women.[8]

Few studies have investigated the roles of glass, pottery and tile work and precision tool manufacturing in ALS.[4, 14, 23] We found a positive association for glass, pottery and tile work and ALS risk in the present study. A previous Swedish study found no association between glass, pottery and tile work and ALS risk.[23] In comparison with our study, which used occupational information from the 1970, 1980 and 1990 Swedish censuses, the previous Swedish study used the 1960 census alone to obtain occupational information.[23] Additionally, the present study identified newly diagnosed ALS cases identified through the NPR, whereas the previous studied deaths due to ALS.[23] A positive association of precision work and ALS was however found in both the present study and earlier studies.[4, 14] One case-control study found a higher risk of motor neuron disease among precision textile, machine workers, [14] and another case-control study found precision production to be related to the risk of ALS.[4]

Limitations of the present study should be noted. We used the Swedish censuses to collect individual occupational history information and included only information collected at ten year intervals. The intervening occupational history within these intervals was not captured. Although we used administrative and clerical work as the reference, we had no information on potential variation in occupational exposure in this group. For example, administrators and clerical workers in factories and auto shops might have different exposure levels compared to those working in schools. Furthermore, different combinations of occupational exposures may coexist in different occupations. Although we mutually adjusted for 12 predefined occupational exposures in the analyses, it is not clear whether other potentially confounding occupational exposures not included in the NOCCA-JEM should have been evaluated and adjusted for when studying these 12 exposures. Finally, given the 20-year study period, we used both ICD-9 (specific for ALS) and ICD-10 (for all motor neuron 
diseases) codes to identify ALS cases in the present study; some patients with motor neuron diseases other than ALS might have been counted as ALS patients. However, since ALS is the most common motor neuron disease, we assumed such misclassification would have minor impact on the study results. Whether or not the revision of the most commonly used ALS diagnostic criteria (El Escorial criteria) during the study period had any impact on the register-based ALS definition remains however to be investigated.

The strengths of our study include the large sample size, nationwide design, and prospective information on occupations and occupational exposures. These features collectively reduced most information and selection biases. Further, the NOCCA-JEM provided us with a unique opportunity to estimate the impact of various workplace exposures specific to Sweden on the risk of ALS.

In conclusion, we found precision-tool manufacturing and glass, pottery and tile work to be positively associated, while textile work was inversely associated, with ALS risk in Sweden. We found that formaldehyde was associated with an increased risk and methylene chloride with a decreased risk of ALS before 65 years of age. Further studies are needed to confirm these findings and clarify potential mechanisms involved.

\section{Supplementary Material}

Refer to Web version on PubMed Central for supplementary material.

\section{Acknowledgments}

\section{Funding}

This study was supported by Swedish Research Council (SIMSAM grant No. 80748301 and Grant No. 2015-03170), FAS (grant No. 2011-0172), the EU Joint Programme - Neurodegenerative Disease Research (JPND) (www.jpnd.eu), Swedish Society for Medical Research (SSMF), the Karolinska Institutet, and the Intramural Research Program of The National Institute of Environmental Health Sciences, National Institutes of Health (Z01ES-049005).

\section{References}

1. Robberecht W, Philips T. The changing scene of amyotrophic lateral sclerosis. Nat Rev Neurosci. 2013; 14:248-64. [Published Online First: 6 March 2013]. DOI: 10.1038/nrn3430 [PubMed: 23463272]

2. Al-Chalabi A, Hardiman O. The epidemiology of ALS: a conspiracy of genes, environment and time. Nat Rev Neurol. 2013; 9:617-28. [Published Online First: 15 October 2013]. DOI: 10.1038/ nrneurol.2013.203 [PubMed: 24126629]

3. Ingre C, Roos PM, Piehl F, et al. Risk factors for amyotrophic lateral sclerosis. Clinical Epidemiology. 2015; 7:181-93. [Published Online First: 12 February 2015]. DOI: 10.2147/ CLEP.S37505 [PubMed: 25709501]

4. Fang F, Quinlan P, Ye W, et al. Workplace exposures and the risk of amyotrophic lateral sclerosis. Environ Health Perspect. 2009; 9:1387-92. [Published Online First: 11 May 2009]. DOI: 10.1289/ ehp.0900580

5. Fang F, Kwee LC, Allen KD, et al. Association between blood lead and the risk of amyotrophic lateral sclerosis. Am J Epidemiol. 2010; 15:1126-33. [Published Online First: 20 April 2010]. DOI: 10.1093/aje/kwq063

6. Kamel F, Umbach DM, Munsat TL, et al. Lead exposure and amyotrophic lateral sclerosis. Epidemiology. 2002; 13:311-9. [PubMed: 11964933] 
7. Morahan JM, Pamphlett R. Amyotrophic lateral sclerosis and exposure to environmental toxins: an Australian case-control study. Neuroepidemiology. 2006; 27:130-5. [PubMed: 16946624]

8. Roberts AL, Johnson NJ, Cudkowicz ME, et al. Job-related formaldehyde exposure and ALS mortality in the USA. J Neurol Neurosurg Psychiatry. 2015; 0:1-2. Published Online First: 13 July 2015. DOI: 10.1136/jnnp-2015-310750

9. Wang MD, Gomes J, Cashman NR, et al. A meta-analysis of observational studies of the association between chronic occupational exposure to lead and amyotrophic lateral sclerosis. J Occup Environ Med. 2014; 56:1235-42. [Published Online First: December 2014]. DOI: 10.1097/JOM. 0000000000000323 [PubMed: 25479292]

10. Gait R, Maginnis C, Lewis S, et al. Occupational exposure to metals and solvents and the risk of motor neuron disease. A case-control study. Neuroepidemiology. 2003; 22:353-6. DOI: 10.1159/000072925 [PubMed: 14557686]

11. Sutedja NA, Veldink JH, Fischer K, et al. Exposure to chemicals and metals and risk of amyotrophic lateral sclerosis: a systematic review. Amyotroph Lateral Scler Frontotemporal Degener. 2009; 10:302-9. [Published Online First: 18 November 2009]. DOI: 10.3109/17482960802455416

12. Fischer H, Kheifets L, Huss A, et al. Occupational Exposure to Electric Shocks and Magnetic Fields and Amyotrophic Lateral Sclerosis in Sweden. Epidemiology. 2015; 26:824-30. DOI: 10.1097/EDE.0000000000000365 [PubMed: 26414853]

13. Longstreth WT, McGuire V, Koepsell TD, et al. Risk of amyotrophic lateral sclerosis and history of physical activity: a population-based case-control study. Arch Neurol. 1998; 55:201-6. [PubMed: 9482362]

14. Park RM, Schulte PA, Bowman JD, et al. Potential occupational risks for neurodegenerative diseases. Am J Ind Med. 2005; 48:63-77. [PubMed: 15940722]

15. Zhou H, Chen G, Chen C, et al. Association between extremely low-frequency electromagnetic fields occupations and amyotrophic lateral sclerosis: a meta-analysis. PLoS One. 2012; $7:$ e48354. [Published Online First: 26 November 2012]. doi: 10.1371/journal.pone.0048354 [PubMed: 23189129]

16. Kauppinen T, Heikkila P, Plato N, et al. Construction of job-exposure matrices for the Nordic Occupational Cancer Study (NOCCA). Acta Oncol. 2009; 48:791-800. DOI: 10.1080/02841860902718747 [PubMed: 19225948]

17. Lagerlund M, Bellocco R, Karlsson P, et al. Socio-economic factors and breast cancer survival--a population-based cohort study (Sweden). Cancer Causes \& Control. 2005; 16:419-30. [PubMed: 15953984]

18. Sutedja NA, Fischer K, Veldink JH, et al. What we truely know about occupation as a risk factor for ALS: a critical and systematic review. Amyotroph Lateral Scler Frontotemporal Degene. 2009; 10:295-301. DOI: 10.3109/17482960802430799

19. Shah D. Heathly worker phenomenon. Indian J Occup Environ Med. 2009; 13:77-9. [Published Online First: 20 August 2009]. DOI: 10.4103/0019-5278.55123 [PubMed: 20386623]

20. D-Maps. Sweden: http://www.d-maps.com/carte.php?num_car=23111\&lang=en [accessed June 2016]

21. Feychting M, Jonsson F, Pedersen NL, et al. Occupational magnetic field exposure and neurodegenerative disease. Epidemiology. 2003; 14:413-9. [PubMed: 12843764]

22. Gunnarsson LG, Bodin L, Soderfeldt B, Axelson O. A case-control study of motor neurone disease: its relation to heritability, and occupational exposures, particularly to solvents. Br J Ind Med. 1992; 49:791-8. [PubMed: 1463680]

23. Gunnarsson LG, Lindberg G, Soderfeldt B, et al. Amyotrophic lateral sclerosis in Sweden in relation to occupation. Acta Neurol Scand. 1991; 83:394-8. [PubMed: 1887762]

24. Malek AM, Barchowsky A, Bowser R, et al. Environmental and occupational risk factors for amyotrophic lateral sclerosis: a case-control study. Neurodegener Dis. 2014; 14:31-8. [Published Online First: 12 November 2013]. DOI: 10.1159/000355344 [PubMed: 24246552]

25. Liu T, Xu QE, Zhang CH, et al. Occupational exposure to methylene chloride and risk of cancer: a meta-analysis. Cancer Causes Control. 2013; 24:2037-49. [Published Online First: 12 September 2013]. DOI: 10.1007/s10552-013-0283-0 [PubMed: 24026192] 
26. Vimercati L, Carrus A, Martino T, et al. Formaldehyde exposure and irritative effects on medical examiners, pathologic anatomy post-graduate students and technicians. Iran J Public Health. 2010; 39:26-34. [PubMed: 23113035]

27. Weisskopf MG, McCullough ML, Morozova N, et al. Prospective study of occupation and amyotrophic lateral sclerosis mortality. Am J Epidemiol. 2005; 162:1146-52. [PubMed: 16269579]

28. Weisskopf MG, Morozova N, O'Reilly EJ, et al. Prospective study of chemical exposures and amyotrophic lateral sclerosis. J Neurol Neurosurg Psychiatry. 2009; 80:558-61. DOI: 10.1136/ jnnp.2008.156976 [PubMed: 19372290] 


\section{What this paper adds}

- $\quad$ No known studies have used a job exposure matrix to examine occupational exposures to solvents, metals or formaldehyde in relation to ALS risk.

- $\quad$ ALS risk was positively associated with precision-tool manufacturing and glass, pottery, and tile work, but inversely associated with textile work.

- $\quad$ ALS diagnosed before retirement ( $<65$ years old) was positively associated with formaldehyde and inversely associated with methylene chloride.

- This study advances our understanding of the associations of occupations and occupational exposures with ALS risk. 


\section{Table 1}

Characteristics of amyotrophic lateral sclerosis cases and controls

\begin{tabular}{|c|c|c|c|c|}
\hline & \multicolumn{2}{|c|}{ Cases $(n=5,020)$} & \multicolumn{2}{|c|}{ Controls $(n=25,100)$} \\
\hline & No. & $\%$ & No. & $\%$ \\
\hline \multicolumn{5}{|l|}{ Gender } \\
\hline Male & 2822 & 56 & 14,110 & 56 \\
\hline Female & 2198 & 44 & 10,990 & 44 \\
\hline \multicolumn{5}{|l|}{ Birth year } \\
\hline $1901-1922$ & 1150 & 23 & 5750 & 23 \\
\hline $1923-1931$ & 1316 & 26 & 6580 & 26 \\
\hline $1932-1941$ & 1233 & 25 & 6165 & 25 \\
\hline 1942-1949 & 775 & 15 & 3875 & 15 \\
\hline $1950-1955$ & 292 & 6 & 1460 & 6 \\
\hline $1955+$ & 254 & 5 & 1270 & 5 \\
\hline \multicolumn{5}{|l|}{ Age at index date, years } \\
\hline$<40$ & 77 & 2 & 381 & 2 \\
\hline $40-49$ & 247 & 5 & 1231 & 5 \\
\hline $50-59$ & 740 & 15 & 3693 & 15 \\
\hline $60-69$ & 1410 & 28 & 7078 & 28 \\
\hline $70-79$ & 1730 & 34 & 8609 & 34 \\
\hline 280 & 816 & 16 & 4108 & 16 \\
\hline \multicolumn{5}{|l|}{ Year at index date } \\
\hline 1991-1995 & 907 & 18 & 4535 & 18 \\
\hline 1996-2000 & 1031 & 21 & 5155 & 21 \\
\hline 2001-2005 & 1510 & 30 & 7550 & 30 \\
\hline 2006-2010 & 1572 & 31 & 7860 & 31 \\
\hline \multicolumn{5}{|l|}{ Education } \\
\hline 9 years or less of education & 2311 & 47 & 12047 & 49 \\
\hline $10-12$ years of education & 1758 & 36 & 8402 & 34 \\
\hline University & 789 & 16 & 3814 & 16 \\
\hline $\mathrm{PhD}$ & 41 & 1 & 138 & 1 \\
\hline Missing & 121 & & 699 & \\
\hline \multicolumn{5}{|l|}{ Region of residence } \\
\hline North Sweden & 1141 & 23 & 5648 & 23 \\
\hline Middle Sweden & 2673 & 53 & 13402 & 53 \\
\hline South Sweden & 1206 & 24 & 6050 & 24 \\
\hline
\end{tabular}

Occup Environ Med. Author manuscript; available in PMC 2017 May 31. 


\section{Table 2}

Occupations held at least 10 years before amyotrophic lateral sclerosis diagnosis and the risk of amyotrophic lateral sclerosis

\begin{tabular}{|c|c|c|c|c|}
\hline & \multirow{2}{*}{$\begin{array}{l}\text { Cases }(N=4567) \\
\text { No. }\end{array}$} & \multirow{2}{*}{$\begin{array}{r}\text { Controls }(\mathrm{N}=\mathbf{2 2 4 0 2}) \\
\text { No. }\end{array}$} & \multicolumn{2}{|c|}{ Adjusted $^{a}$} \\
\hline & & & OR & $95 \% \mathrm{CI}$ \\
\hline Administration and Clerical Work & 410 & 2078 & & Reference \\
\hline Transport and Communications Work & 395 & 2038 & 0.96 & $0.84-1.08$ \\
\hline Service Work & 747 & 3558 & 1.03 & $0.93-1.14$ \\
\hline Sales Work & 593 & 2915 & 1.00 & $0.90-1.11$ \\
\hline Chemical and Physical Work & 42 & 207 & 1.00 & $0.71-1.40$ \\
\hline Biological Work & 13 & 49 & 1.28 & $0.69-2.36$ \\
\hline Medical Work & 39 & 147 & 1.27 & $0.88-1.84$ \\
\hline Health and Nursing Work & 370 & 1610 & 1.13 & $0.99-1.29$ \\
\hline Agricultural, Forestry and Fishing Work & 355 & 1912 & 0.91 & $0.80-1.03$ \\
\hline Mining and Quarrying Work & 19 & 76 & 1.30 & $0.78-2.16$ \\
\hline Textile Work & 8 & 81 & 0.44 & $0.21-0.91$ \\
\hline Sewing Work & 54 & 274 & 0.98 & $0.73-1.32$ \\
\hline Shoe and Leather Goods Work & 10 & 49 & 1.07 & $0.54-2.14$ \\
\hline Metal Processing Work & 55 & 249 & 1.11 & $0.82-1.50$ \\
\hline Precision-Tool Manufacturing Work & 32 & 94 & 1.68 & $1.11-2.52$ \\
\hline Engineering and Building Metal Work & 437 & 2150 & 1.00 & $0.88-1.12$ \\
\hline Wood Work & 195 & 969 & 1.01 & $0.85-1.19$ \\
\hline Painting Work & 52 & 239 & 1.06 & $0.78-1.44$ \\
\hline Other Building and Construction Work & 113 & 604 & 0.93 & $0.75-1.15$ \\
\hline Printing Work & 40 & 250 & 0.79 & $0.56-1.11$ \\
\hline Glass, Pottery and Tile Work & 19 & 52 & 1.76 & $1.03-3.00$ \\
\hline Food Processing Work & 58 & 299 & 0.94 & $0.70-1.26$ \\
\hline Chemical and Cellulose Processing Work & 40 & 243 & 0.81 & $0.57-1.13$ \\
\hline Other Production and Related Work & 51 & 313 & 0.81 & $0.60-1.09$ \\
\hline Unskilled Manual Work & 43 & 275 & 0.78 & $0.56-1.09$ \\
\hline Operations Monitoring, Material Handling Work & 108 & 602 & 0.91 & $0.74-1.13$ \\
\hline Packing, Freight Handling and Storage Work & 143 & 730 & 0.98 & $0.82-1.19$ \\
\hline Armed Forces & 31 & 195 & 0.77 & $0.52-1.14$ \\
\hline Other & 1146 & 5538 & 1.00 & $0.91-1.10$ \\
\hline
\end{tabular}

${ }^{a}$ Adjusted for age and gender (matching factors) and education 
Table 3

Exposures in occupations held at least 10 years before amyotrophic lateral sclerosis diagnosis and the risk of amyotrophic lateral sclerosis

\begin{tabular}{|c|c|c|c|c|}
\hline & \multirow{2}{*}{$\begin{array}{l}\text { Cases }(N=2647) \\
\text { No. }\end{array}$} & \multirow{2}{*}{$\begin{array}{r}\text { Controls }(\mathrm{N}=13378) \\
\text { No. }\end{array}$} & \multicolumn{2}{|c|}{ Adjusted $^{a}$} \\
\hline & & & OR & $95 \%$ CI \\
\hline No Exposure & 1787 & 9104 & & Reference \\
\hline Lead & 611 & 3052 & 1.07 & $0.85-1.35$ \\
\hline Formaldehyde & 323 & 1579 & 1.07 & $0.92-1.25$ \\
\hline Iron & 453 & 2232 & 0.95 & $0.44-2.03$ \\
\hline Nickel & 453 & 2240 & 0.93 & $0.46-1.88$ \\
\hline Trichloroethylene & 280 & 1338 & 1.10 & $0.82-1.47$ \\
\hline Methylene chloride & 273 & 1478 & 0.87 & $0.59-1.30$ \\
\hline Chromium & 506 & 2484 & 1.18 & $0.82-1.69$ \\
\hline Perchloroethylene & 70 & 336 & 1.03 & $0.66-1.62$ \\
\hline Toluene & 230 & 1257 & 0.90 & $0.44-1.82$ \\
\hline Benzene & 245 & 1313 & 1.12 & $0.61-2.04$ \\
\hline Benzo (a) pyrene & 361 & 1856 & 0.99 & $0.75-1.31$ \\
\hline 1,1,1-Trichloroethane & 417 & 2173 & 0.89 & $0.65-1.23$ \\
\hline
\end{tabular}

${ }^{a}$ Adjusted for age and gender (matching factors) and education. The 12 occupational exposures were mutually adjusted for one another. 


\section{Table 4}

Grouped occupational exposures and amyotrophic lateral sclerosis risk

\begin{tabular}{lrrrrr}
\hline & \multicolumn{2}{c}{ Cases $(\mathbf{N}=\mathbf{2 6 4 7})$} & Controls $(\mathbf{N}=\mathbf{1 3 3 7 8})$ & \multicolumn{2}{c}{ Adjusted $^{\boldsymbol{a}}$} \\
& No. & & No. & OR & $\mathbf{9 5 \%} \mathbf{~ C I}$ \\
\hline No exposure & 1787 & 9104 & & Reference \\
Metals + benzo (a) pyrene & $b$ & 651 & 3243 & 1.07 & $0.91-1.26$ \\
Solvents & $c$ & 489 & 2496 & 0.92 & $0.77-1.09$ \\
Formaldehyde & 323 & 1579 & 1.07 & $0.93-1.23$ \\
\hline
\end{tabular}

${ }^{a}$ Adjusted for age and gender (matching factors) and education. The three occupational exposure groups were mutually adjusted for one another.

$b_{\text {Includes lead, iron, nickel, chromium, benzo (a) pyrene }}$

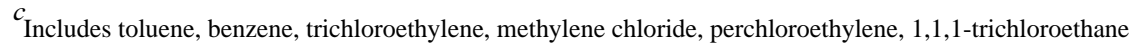




\section{Table 5}

Dose-response relationships of amyotrophic lateral sclerosis with lead and formaldehyde

\begin{tabular}{|c|c|c|c|c|}
\hline & \multirow{2}{*}{$\begin{array}{l}\text { Cases } \\
\text { No. }\end{array}$} & \multirow{2}{*}{$\begin{array}{l}\text { Controls } \\
\text { No. }\end{array}$} & \multicolumn{2}{|l|}{ Adjusted $^{a}$} \\
\hline & & & OR & $95 \%$ CI \\
\hline \multicolumn{5}{|c|}{ Whole Population } \\
\hline \multicolumn{5}{|l|}{ Lead $b$} \\
\hline No Exposure & 1828 & 9269 & Reference & \\
\hline$\leq 0.115$ & 321 & 1567 & 1.03 & $0.76-1.40$ \\
\hline$>0.115$ & 274 & 1401 & 1.01 & $0.78-1.30$ \\
\hline \multicolumn{5}{|l|}{ Formaldehyde $b$} \\
\hline No Exposure & 1828 & 9269 & Reference & \\
\hline$\leq 0.013$ & 97 & 550 & 0.91 & $0.72-1.16$ \\
\hline$>0.013$ & 123 & 574 & 1.22 & $0.95-1.57$ \\
\hline \multicolumn{5}{|c|}{$<65$ Years of Age } \\
\hline \multicolumn{5}{|l|}{ Lead $^{b}$} \\
\hline No Exposure & 659 & 3341 & Reference & \\
\hline$\leq 0.106$ & 136 & 626 & 1.04 & $0.66-1.65$ \\
\hline$>0.106$ & 143 & 626 & 1.29 & $0.88-1.90$ \\
\hline \multicolumn{5}{|l|}{ Formaldehyde $b$} \\
\hline No Exposure & 659 & 3341 & Reference & \\
\hline$\leq 0.013$ & 30 & 185 & 0.89 & $0.58-1.36$ \\
\hline$>0.013$ & 53 & 210 & 1.31 & $0.86-1.99$ \\
\hline
\end{tabular}

${ }^{a}$ Adjusted for age and gender (matching factors), education, iron/welding fumes, nickel, trichloroethylene, methylene chloride, chromium, perchloroethylene, toluene, benzene, benzo (a) pyrene, 1,1,1-trichloroethane

$b_{\text {Categorized based on median among controls }}$ 